\title{
Serum Interleukin 6 Is Predictive of Early Functional Decline and Mortality in Interstitial Lung Disease Associated with Systemic Sclerosis
}

\author{
Angelo De Lauretis, Piersante Sestini, Panagiotis Pantelidis, Rachel Hoyles, David M. Hansell, \\ Nicole S.L. Goh, Christopher J. Zappala, Dina Visca, Toby M. Maher, Christopher P. Denton, \\ Voon H. Ong, David J. Abraham, Peter Kelleher, Laureen Hector, Athol U. Wells, \\ and Elisabetta A. Renzoni
}

\begin{abstract}
Objective. Biomarkers of progression of interstitial lung disease (ILD) are needed to allow early therapeutic intervention in patients with scleroderma-associated disease (SSc-ILD).

Methods. A panel of 8 serum cytokines [interleukin 6 (IL-6), IL-8, IL-10, CCL2, CXCL10, vascular endothelial growth factor, fibroblast growth factor 2, and CX3CL1] was assessed by Luminex bead technology in exploratory cohorts of 74 patients with SSc and 58 patients with idiopathic pulmonary fibrosis (IPF). Mortality and significant lung function decline [forced vital capacity (FVC) $\geq 10 \%$; $\mathrm{DLCO} \geq 15 \%$ ] from date of serum collection were evaluated by proportional hazards analysis. Based on these findings, the prognostic value of serum IL-6, evaluated by ELISA, was assessed in a larger test cohort of 212 patients with SSc-ILD.

Results. In the exploratory cohort, only serum IL-6 was an independent predictor of DLCO decline in both IPF and SSc-ILD. The IL-6 threshold level most predictive of DLCO decline within a year was $7.67 \mathrm{pg} / \mathrm{ml}$. In the larger test cohort, serum IL-6 $>7.67 \mathrm{pg} / \mathrm{ml}$ was predictive of decline in FVC (HR $2.58 \pm 0.98, \mathrm{p}=0.01)$ and in DLCO (HR $3.2 \pm 1.7, \mathrm{p}=0.02)$ within the first year, and predictive of death within the first 30 months (HR $2.69 \pm 0.96, \mathrm{p}=0.005$ ). When stratified according to severity (FVC $<70 \%$ ), serum IL-6 $>7.67 \mathrm{pg} / \mathrm{ml}$ was predictive of functional decline or death within the first year in patients with milder disease (OR 3.1,95\% CI 1.4-7.2, p=0.007), but not in those with severe ILD.

Conclusion. In SSc-ILD, serum IL-6 levels appear to be predictive of early disease progression in patients with mild ILD, and could be used to target treatment in this group, if confirmed by prospective studies. (J Rheumatol First Release Feb 1 2013; doi:10.3899/jrheum.120725)
\end{abstract}

Key Indexing Terms:

\section{SCLERODERMA PULMONARY FIBROSIS INTERLEUKIN 6 SERUM BIOMARKERS}

Systemic sclerosis (SSc) is an autoimmune condition characterized by tissue fibrosis of the skin and internal organs. Interstitial lung disease associated with SSc
(SSc-ILD) accounts for about one-third of deaths ${ }^{1,2,3}$. Clinical variables associated with a higher risk of progression of SSc-ILD include severity of lung
From the Department of Pneumology, Carlo Poma Hospital, Mantua, Italy; Department of Pneumology, Università Cattolica del Sacro Cuore, Rome, Italy; Department of Respiratory Medicine, University of Siena, Ospedale "Le Scotte," Siena, Italy; Infection and Immunity Laboratory, Imperial College Healthcare NHS Trust, Charing Cross Hospital, London, UK; Centre for Rheumatology and Connective Tissue Diseases, UCL Medical School, Royal Free Hospital, London, UK; Department of Radiology, Royal Brompton Hospital, London, UK; Respiratory and Sleep Medicine, Austin Health, Melbourne, Australia; Interstitial Lung Disease Unit, Royal Brompton Hospital, London, UK; and the Immunology Section, Division of Infectious Diseases, Imperial College, Chelsea and Westminster Hospital, London, UK.

Supported by the European Respiratory Society Short-Term Research Fellowship grant ERS-STRF 595 and by the Raynaud's and Scleroderma Association; and by the NIHR Respiratory Disease Biomedical Research Unit at the Royal Brompton and Harefield NHS Foundation Trust and Imperial College London. Dr. Sestini was supported by MIUR project no. $2008 W 7 X P 29$.

A. De Lauretis, MD, Department of Pneumology, Carlo Poma Hospital, Department of Pneumology, Università Cattolica del Sacro Cuore; P. Sestini, MD, Department of Respiratory Medicine, University of Siena, Ospedale "Le Scotte"; P. Pantelidis, PhD, Infection and Immunity

\begin{abstract}
Laboratory, Imperial College Healthcare NHS Trust, Charing Cross
Hospital; R. Hoyles, MD, PhD, Centre for Rheumatology and Connective Tissue Diseases, UCL Medical School, Royal Free Hospital; D.M. Hansell, MD, FRCP, FRCR, Department of Radiology, Royal Brompton Hospital; N.S.L. Goh, MD, PhD, Respiratory and Sleep Medicine, Austin Health; C.J. Zappala, MD, FRACP, Interstitial Lung Disease Unit, Royal Brompton Hospital; D. Visca, MD, Department of Pneumology, Università Cattolica del Sacro Cuore; T.M. Maher, MRCP, PhD, Interstitial Lung Disease Unit, Royal Brompton Hospital; C.P. Denton, $M D, P h D ;$ V.H. Ong, PhD, MRCP; D.J. Abraham, PhD, Centre for Rheumatology and Connective Tissue Diseases, UCL Medical School, Royal Free Hospital; P. Kelleher, PhD, Infection and Immunity Laboratory, Imperial College Healthcare NHS Trust, Charing Cross Hospital, Immunology Section, Division of Infectious Diseases, Imperial College, Chelsea and Westminster Hospital; L. Hector, BSc, PhD, Infection and Immunity Laboratory, Imperial College Healthcare NHS Trust, Charing Cross Hospital; A.U. Wells, FRACP, MD, FRCP, FRCR; E.A. Renzoni, MD, PhD, Interstitial Lung Disease Unit, Royal Brompton Hospital.

Address correspondence to Dr. E. Renzoni, Interstitial Lung Disease Unit, Royal Brompton Hospital, Emmanuel Kaye Building, 1 B Manresa Road, LondonSW3 6LR, UK. E-mail: e.renzoni@imperial.ac.uk

Accepted for publication December 4, 2012.
\end{abstract}


involvement and a diagnosis of SSc within the previous 4 years ${ }^{4}$. Recently, Goh and co-authors have proposed a simple 2-stage "mild"/"extensive" system to identify SSc-ILD patients with a worse prognosis, based on rapid assessment of the extent of disease on high-resolution computed tomography (HRCT) with recourse, in "indeterminate" cases, to lung-function data ${ }^{5}$. In addition, a marker of epithelial injury has recently been observed to predict likelihood of lung function decline in SSc-ILD, independently of disease severity, in a large number of patients with $\mathrm{SSc}^{6}$.

Although these studies signal significant advances in our ability to predict behavior of lung disease in the context of $\mathrm{SSc}$, additional noninvasive markers of likelihood of disease progression are needed to target patients with SSc-ILD at risk of progression. In particular, in mild disease there is a need to identify patients at higher risk of progression to extensive disease with a view to early protective therapy. Among serum biomarkers linked to lung fibrosis in SSc, the most studied have been markers of epithelial cell damage, including KL-6 and surfactant ${ }^{7,8}$. However, to our knowledge, there has been only 1 large study specifically investigating whether serum biomarkers identify progressive disease, once lung disease severity has been taken into account ${ }^{9}$.

We conducted an exploratory analysis with a panel of 8 serum cytokines using a multianalyte assay system in 74 patients with SSc. As an additional disease group, we also studied 58 patients with idiopathic pulmonary fibrosis (IPF), the most common idiopathic ILD, characterized by a significantly worse prognosis than SSc-ILD ${ }^{10}$. The cytokines were selected on the basis of published data suggesting links with lung fibrosis and previous investigations in our laboratory ${ }^{11,12}$. We then selected serum interleukin 6 (IL-6) to be tested further as a predictor of progression of lung disease and mortality in a larger cohort of 212 patients with SSc-ILD.

\section{MATERIALS AND METHODS}

Patients. Patients with SSc met American Rheumatism Association preliminary criteria for a diagnosis of $\mathrm{SSc}^{13}$, with the exclusion of those with "overlap" connective tissue disorders. Patients with IPF met the American Thoracic Society/European Respiratory Society (ATS/ERS) diagnostic criteria ${ }^{14}$. In both disease groups, patients were excluded if they had overt concurrent malignant disease, severe heart disease, and severe pulmonary hypertension associated with right heart failure.

Exploratory cohort. The discovery cohort consisted of 74 patients with SSc and 58 patients with IPF evaluated at the Interstitial Lung Disease Unit, Royal Brompton Hospital, London, from whom serum samples had been collected at first presentation, between January 1991 and August 2006. Control samples were obtained from 20 nonsmoking healthy volunteers. Serum levels of 8 cytokines were assessed as described below.

Test cohort. To test associations between serum IL-6 and ILD progression and survival, we assessed a second group of 212 patients with SSc-ILD seen at the Royal Brompton Hospital and/or the Royal Free Hospital, London. Serum was collected from these patients from February 1982 to October 2004.

Blood $(10 \mathrm{ml})$ was drawn from all patients using standardized phlebotomy procedures. Serum was separated by centrifugation, and all specimens were immediately aliquoted and stored at $-80^{\circ} \mathrm{C}$.
Clinical data. Of the 74 patients with SSc (first set), 20 had no or trivial ILD (average extent on CT $<5 \%$ ). Investigations were carried out as part of a routine clinical protocol. Informed consent and ethical approval from the Royal Brompton and Royal Free Hospital Ethics Committee were obtained for both sets.

Pulmonary function tests, HRCT, echocardiography, and ${ }^{99 \mathrm{~m} T c-t e c h n e-}$ tium-labeled diethylene-triamine-pentacetate (DTPA) clearance were performed as reported ${ }^{15,16,17}$. Ever-smokers were defined as individuals who had smoked $>1$ cigarette/day for at least 1 year. Treatment was defined as corticosteroid (prednisolone $\geq 1 \mathrm{mg} /$ day) and/or immunosuppressant (cyclophosphamide, azathioprine, mycophenolate) therapy. Pulmonary hypertension was defined as estimated right ventricular systolic pressure $\geq 40 \mathrm{~mm} \mathrm{Hg}$ on echocardiogram. Erythrocyte sedimentation rates (ESR) within 6 months from serum collection were available for 35 IPF patients (60\%) and $54 \mathrm{SSc}$ patients (73\%) in the exploratory set, and for $168 \mathrm{SSc}$ patients in the test set $(79 \%)$.

Initial lung function assessment was performed within 3 months of serum collection for all patients in the exploratory set. In the test set of 212 patients, lung function assessment within 6 months of serum collection was available for 172 patients, and within 12 months in the others. The composite physiologic index (CPI), a functional index of lung fibrosis severity, was calculated as follows: $\mathrm{CPI}=91.0-(0.65 \times$ DLCO \%pred $)-$ $(0.53 \times$ FVC $\%$ pred $)+(0.34 \times \text { FEV1 } \% \text { pred })^{18}$, and was available for all patients. Although initially developed in IPF, the CPI has subsequently been used as an index of severity in SSc-ILD ${ }^{6}$ and in other ILD ${ }^{19}$. CPI was used as a continuous variable in multivariate analyses to adjust for ILD severity. Further, patients were stratified into those with mild and those with severe ILD depending on a threshold for FVC of $70 \%$, chosen as the functional severity threshold most predictive of disease progression in $\mathrm{SSc}_{\mathrm{ILD}}$. In the test set of patients, DTPA clearance measures were available within 6 months of serum collection in 110 patients.

Functional deterioration ("time to decline") was identified using ATS/ERS criteria $(\geq 10 \% \text { decline in FVC, } \geq 15 \% \text { decline in DLCO })^{20}$ and quantified as described ${ }^{16}$. It was considered clinically significant when observed on at least 2 consecutive occasions. When followup ended with functional deterioration on a single occasion, it was accepted as significant decline only if there was symptomatic and/or HRCT evidence of worsening. "Time to decline" was assessed only in patients who had lung function testing within 6 months of serum collection and for whom longitudinal lung function data were available ( $\mathrm{n}=116$ in the exploratory set; $\mathrm{n}$ $=172$ in the test set). Progression-free survival, defined as the time to functional decline (of FVC and/or DLCO) or death, was also assessed. Clinical characteristics of both patient sets are shown in Table 1.

Detection of serum proteins. In the exploratory set, an 8-plex assay was performed for IL-6, IL-8, chemokine (C-C motif) ligand 2 (CCL2/MCP-1), IL-10, chemokine (C-X-C motif) ligand 10 (CXCL10/IP-10), vascular endothelial growth factor, fibroblast growth factor 2, and chemokine (C-X3-C motif) ligand 1 (CX3CL1/fractalkine). Assays were performed using fluorescent bead-based technology (Luminex Corp.) in 96-well microplate format, in compliance with the kit manufacturer's instructions, as described ${ }^{11}$. The fluorescent beads were obtained from Millipore. Antibody-conjugated beads were prepared and aliquoted into a 96-well prewetted filter plate, before addition of either $100 \mu 1$ standard solution in the designated wells or $100 \mu 1$ serum, diluted 1:2 with assay diluent. Subsequent steps involved washes interspersed by the addition of biotinylated detector antibody and later streptavidin-RPE solution. Finally, the plate was placed on the XY platform of the Luminex 100 instrument for analysis. StarStation software was used for data acquisition and analysis. Standard curves were generated for each analyte, and the mean fluorescence intensity value of each analyte in each well was converted into a concentration using the linear portion of the standard for all detected values. This value was then multiplied by the dilution coefficient 2 to give the concentration of the analyte in the original serum.

In the test set, quantitative sandwich enzyme immunoassay for human 
Table 1. Patient characteristics.

\begin{tabular}{|c|c|c|c|c|}
\hline & $\begin{array}{l}\text { Controls, } \\
\mathrm{n}=20\end{array}$ & $\begin{array}{c}\mathrm{IPF} \\
\mathrm{n}=58\end{array}$ & $\begin{array}{l}\text { SSc (exploratory set), } \\
\mathrm{n}=74\end{array}$ & $\begin{array}{l}\text { SSc (test set) } \\
\mathrm{n}=212\end{array}$ \\
\hline Sex female, n $(\%)$ & $7(35)$ & $14(24.1)$ & $59(79.7)^{* \dagger}$ & $165(77.8)$ \\
\hline Age, mean (SD) & $32.7(6.3)$ & $61.1(7.3)^{\dagger}$ & $51.4(12.1)^{* \dagger}$ & $50.9(12.6)$ \\
\hline Smoking, current/former, $\mathrm{n}(\%)$ & $0 / 0$ & $4(6.9) / 37(63.8)^{\dagger}$ & $4(5.5) / 28(38.4)^{* \dagger}$ & $19(9.2) / 69(33.3)$ \\
\hline Followup, mo, median & - & 37.3 & $76.9^{*}$ & 60.5 \\
\hline \multicolumn{5}{|l|}{ Deceased, $\mathrm{n}(\%)$} \\
\hline 3-year mortality & & $19(32.8)$ & $8(10.8)$ & $28(13)$ \\
\hline 5-year mortality & & $34(58.6)$ & $10(13.5)$ & $43(20.3)$ \\
\hline $\begin{array}{l}15 \% \text { DLCO decline**, n }(\%) / \\
\text { median mo }\end{array}$ & - & $39(68.4) / 14.5$ & $34(48.6) / 34.5$ & $90(52.3) / 41.3$ \\
\hline $\begin{array}{l}10 \% \mathrm{FVC} \text { decline**, } \mathrm{n}(\%) / \\
\text { median mo }\end{array}$ & - & $43(69.4) / 14$ & $30(46.2) / 34.8$ & $84(48.8) / 39.5$ \\
\hline $\begin{array}{l}\text { Progression-free survival } * * \dagger \dagger, \\
\mathrm{n}(\%) / \text { median mo }\end{array}$ & - & $39(72.2) / 15.7$ & $42(57.5) / 35$ & $132(71.4) / 40.3$ \\
\hline \multicolumn{5}{|l|}{ Lung function, mean (SD) } \\
\hline FVC, $\%$ predicted & - & $76.9(22.6)$ & $80.3(22.7)$ & $80.6(23.2)$ \\
\hline FEV1, \% predicted & - & $79.4(21.4)$ & $78.6(20.0)$ & $78.2(19.7)$ \\
\hline DLCO, $\%$ predicted & - & $45.9(16.8)$ & $56.2(18.8)^{*}$ & $53.6(18.2)$ \\
\hline CPI, mean (SD) & - & $47.3(14.9)$ & $38.6(17.4)^{*}$ & $40.1(16.4)$ \\
\hline ATA/ACA antibodies, n (\%) & - & $0(0)$ & $31(41.9) / 11(14.86)^{*}$ & $89(41.9) / 33(15.7)$ \\
\hline ESR, mean (SD) & - & $19.2(16)$ & $25.6(22.6)$ & $24.3(20.7)$ \\
\hline dcSSc, n $(\%)$ & - & - & $26(37)$ & $83(40.1)$ \\
\hline DTPA, mean (SD) & - & - & $44.7(29.8)$ & $40.1(25.2)$ \\
\hline
\end{tabular}

$* \mathrm{p}<0.05$ vs IPF. ${ }^{\dagger}$ vs controls. $* *$ Measures were calculated in 172 patients for whom longitudinal lung function data were available from the time of serum collection, all with initial lung function testing within 6 months of serum collection. ${ }^{\dagger \dagger}$ Defined as the time to functional decline (of FVC and/or DLCO) or death. IPF: idiopathic pulmonary fibrosis; SSc: systemic sclerosis; CT: computed tomography scan; FVC: forced vital capacity; FEV1: forced expiratory volume 1 second; CPI: composite physiologic index ${ }^{18}$ : dcSSc: diffuse cutaneous SSc; DTPA: ${ }^{99 \mathrm{~m} T c-t e c h n e t i u m-l a b e l e d ~ d i e t h y l e n e-t r i a m i n e-p e n t a c e t a t e ~ c l e a r a n c e ; ~ A T A: ~ a n t i t o p o i s o m e r a s e ~ a n t i b o d i e s ; ~ A C A: ~}$ anticentromere antibodies; ESR: erythrocyte sedimentation rate.

IL-6 was performed as recommended by the manufacturer (R\&D Systems) in 212 serum samples from patients with SSc.

Statistical analysis. All data are shown as medians or geometric means, unless otherwise indicated. Serum cytokine levels were log-transformed to improve normality of the data distribution and homoscedasticity of variances. The Wilcoxon rank-sum test or chi-square test was used to compare clinical characteristics and cytokine levels between different clinical groups, as appropriate. Spearman's rank correlation, phi correlation, or point-biserial coefficient of correlation, as appropriate, were used to analyze relationships among cytokine levels and between cytokine levels and severity indices. Serum biomarkers were examined against mortality and functional decline using Cox proportional hazard analysis. Aalen's linear hazard model was used to estimate temporal variations of regression coefficients $^{21}$. Age, sex, smoking status, and lung disease severity (CPI) were included in all models. DTPA data were considered only when available within 6 months from the serum sample. To determine the optimal threshold predictive of disease progression, the point on the receiver-operator curve (ROC) with the maximum Youden index (Youden index $=$ sensitivity + specificity -1$)$ was calculated. Analyses were performed using Stata 10.1 and $p$ values $\leq 0.05$ were considered statistically significant. In the exploratory set, to account for multiple testing, $p$ values were corrected by the number of cytokines tested $\left(p_{c}=\right.$ Bonferroni-corrected $\mathrm{p}$ value).

\section{RESULTS}

Serum cytokines in the exploratory set. Serum cytokine levels in SSc and IPF patients and controls are shown in Table 2. After Bonferroni correction for multiple testing, serum levels of IL-6 and CXCL10 remained significantly higher in both SSc and IPF patients compared to controls (IL-6: SSc vs control, $\mathrm{p}_{\mathrm{c}}=0.01$; IPF vs control, $\mathrm{p}_{\mathrm{c}}=0.02$; CXCL10: SSc vs control, $\mathrm{p}_{\mathrm{c}}=0.01$; IPF vs control, $\mathrm{p}_{\mathrm{c}}<$ $0.0008)$. CCL2 was significantly higher in $\operatorname{IPF}\left(\mathrm{p}_{\mathrm{c}}=0.002\right)$, while bordering on significance in $\operatorname{SSc}\left(\mathrm{p}_{\mathrm{c}}=0.054\right)$, compared to controls (Table 2, Appendix 1). Observed differences in other cytokine levels between SSc, IPF, and control groups did not reach statistical significance after Bonferroni correction (uncorrected $\mathrm{p}$ values in Table 2). Details on correlations among serum cytokines and between cytokines, ESR, and lung function measures are given in Appendix 2.

The relationship between serum cytokine levels and disease deterioration was evaluated in both diseases. On univariate analysis, after Bonferroni correction, only serum IL-6 was significantly predictive of DLCO deterioration in both IPF and SSc $\left(\mathrm{p}_{\mathrm{c}}=0.02\right.$; Table 3$)$. CCL2 was associated with progression-free survival only in patients with IPF $\left(\mathrm{p}_{\mathrm{c}}\right.$ $=0.008$; Table 3 ). Although significant associations were observed between other cytokines and disease progression (Table 3), statistical significance was lost after Bonferroni correction. No association was seen between ESR levels and disease progression or survival. 
Table 2. Serum cytokine levels in controls and patients with IPF and SSc (exploratory set). All cytokine levels are expressed as geometric means (95\% CI), except for FGF2 and CX3CL1, analyzed as percentage present greater than threshold value of detection (> $80 \mathrm{pg} / \mathrm{ml}$ for FGF2, > $400 \mathrm{pg} / \mathrm{ml}$ for CX3CL1).

\begin{tabular}{lccc}
\hline Cytokine & Controls & IPF & SSc \\
\hline IL-6, pg/ml & $3(2.1-4.5)$ & $7.3(5.1-10.2)^{* * \dagger \dagger}$ & $8.0(5.8-10.9)^{* * \dagger \dagger}$ \\
IL-8, pg/ml & $30.2(10.0-91.1)$ & $51.8(29.4-91.5)$ & $26.0(17.0-39.7)$ \\
CCL2, pg/ml & $529.8(387.5-724.3)$ & $876.9(757.0-1015.7)^{* * \dagger \dagger}$ & $672.5(537.6-841.1)^{* * \dagger}$ \\
IL-10, pg/ml & $2.7(2.5-3.0)$ & $3.7(3.1-4.4)^{*}$ & $4.8(3.7-6.2)^{*}$ \\
CXCL10, pg/ml & $416.5(347.6-499.1)$ & $764.5(643.2-908.6)^{* * * \dagger \dagger}$ & $638.1(469.4-867.4)^{* * \dagger \dagger}$ \\
VEGF, pg/ml & $145.2(101.6-207.4)$ & $236.1(190.9-292.1)^{*}$ & $212.9(169.9-266.9)$ \\
FGF2, \% & $10(0-20)$ & $19(0-30)$ & $26(20-40)$ \\
CX3CL1, $\%$ & $10(0-20)$ & $9(0-20)$ & $20(10-30)$ \\
\hline
\end{tabular}

CCL2: chemokine (C-C motif) ligand 2; CXCL10: chemokine (C-X-C motif) ligand 10; VEGF: vascular endothelial growth factor; FGF2: fibroblast growth factor 2; CX3CL1: chemokine (C-X3-C motif) ligand 1; IPF: idiopathic pulmonary fibrosis; SSc: systemic sclerosis. * $\mathrm{p}=0.01-0.05 ; * * \mathrm{p}=0.0001-0.01 ; * * \mathrm{p} \leq 0.0001 \mathrm{vs}$ controls; ${ }^{\dagger} \mathrm{p}=0.02$ vs IPF: ${ }^{\dagger \dagger} \mathrm{p}<0.05$ after Bonferroni correction. IL: interleukin.

Table 3. Relationship between serum cytokine levels and functional decline/mortality in SSc and IPF patients on univariate analysis (exploratory set). The relationship is expressed as hazard ratio (HR).

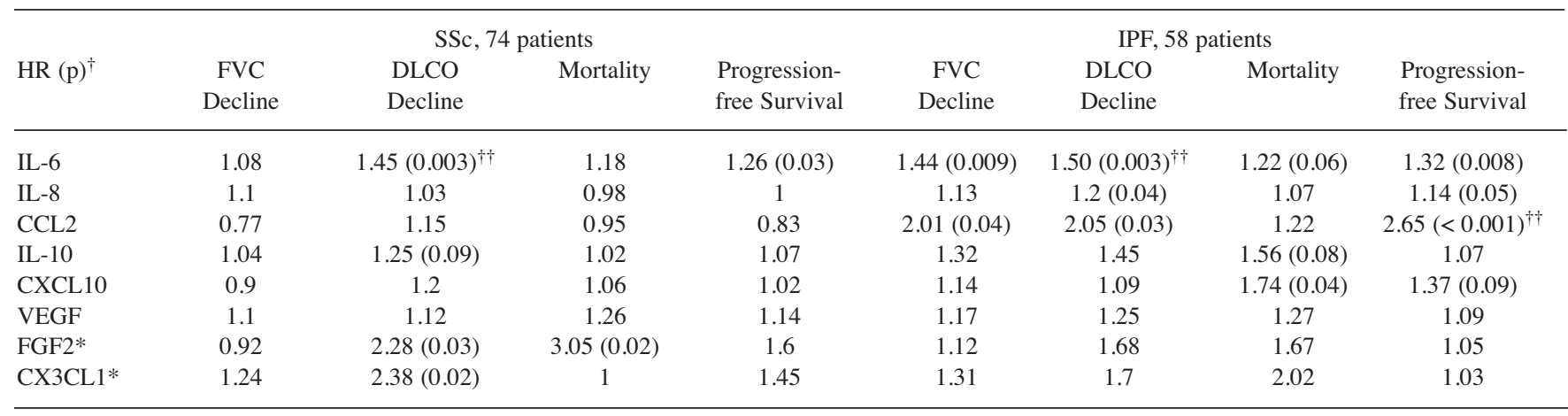

${ }^{\dagger} \mathrm{p}$ values reported in parentheses when $<0.01 .{ }^{\dagger \dagger} \mathrm{p}<0.05$ after Bonferroni correction. * Analyzed as dichotomous variables. CCL2: chemokine (C-C motif) ligand 2; CXCL10: chemokine (C-X-C motif) ligand 10; VEGF: vascular endothelial growth factor; FGF2: fibroblast growth factor 2; CX3CL1: chemokine (C-X3-C motif) ligand 1; IPF: idiopathic pulmonary fibrosis; SSc: systemic sclerosis; FVC: forced vital capacity; IL: interleukin.

On multivariate analysis, after adjustment for age, sex, smoking history, pulmonary hypertension, and severity of lung disease (CPI index), IL-6 remained an independent predictor of irreversible decline in DLCO in both IPF (HR = $1.38, \mathrm{p}=0.05)$ and $\mathrm{SSc}(\mathrm{HR}=2.0, \mathrm{p}=0.002)$ and progression-free survival $(\mathrm{HR}=1.69, \mathrm{p}=0.003)$ in patients with IPF. CCL2 was an independent predictor of progression-free survival $(\mathrm{HR}=2.4, \mathrm{p}=0.003)$ in IPF, but not in patients with SSc.

As serum IL-6 was associated with shorter time to decline in DLCO in both SSc and IPF, threshold analysis was performed on the combined group (ROC analysis). The threshold level of serum IL-6 most predictive of DLCO decline within a year was $7.67 \mathrm{pg} / \mathrm{ml}$ (area under the curve $=0.6$, sensitivity $53 \%$, specificity $71 \%$, Youden index 10.24).

Test set in a larger cohort of patients with SSc. In view of the observed association between IL- 6 and lung function decline in both SSc and IPF, serum IL-6 was selected for further testing in a test set of 212 patients with SSc-ILD.
Demographic and clinical data of the test set are summarized in Table 1. Age, sex, smoking status, and functional status were not significantly different compared to the exploratory SSc group. Sixty of 212 patients died (28.3\%) during a median followup of 60.5 months; 5 -year survival was $79.7 \%$. Decline in FVC was seen in $84(48.8 \%)$ of 172 patients, with a median time to decline of 39.5 months. Decline in DLCO was seen in $90(52.3 \%)$ of 172 patients, with a median time to decline of 41.3 months. Progression-free survival, defined as time until death or worsening in FVC and/or DLCO, was observed in 132 patients (71.4\%), with a median progression-free survival of 40.3 months.

Serum IL-6 analyzed as a continuous variable: association with survival and lung function decline. Analyzed as a continuous variable, IL-6 levels were significantly associated to shorter survival $(\mathrm{HR}=1.32,95 \% \mathrm{CI}$ $1.08-1.62, \mathrm{p}=0.007)$ and decreased time to decline in FVC $(\mathrm{HR}=1.34,95 \%$ CI $1.12-1.61, \mathrm{p}=0.001)$, while a nonsignificant trend was seen for DLCO (HR $=1.14,95 \%$ CI $0.96-1.36, p=0.1$; Table 4). After adjustment for the 
Table 4. Lung function worsening and mortality, expressed as hazard ratio (HR), in relation to baseline findings in the validation set (univariate analysis).

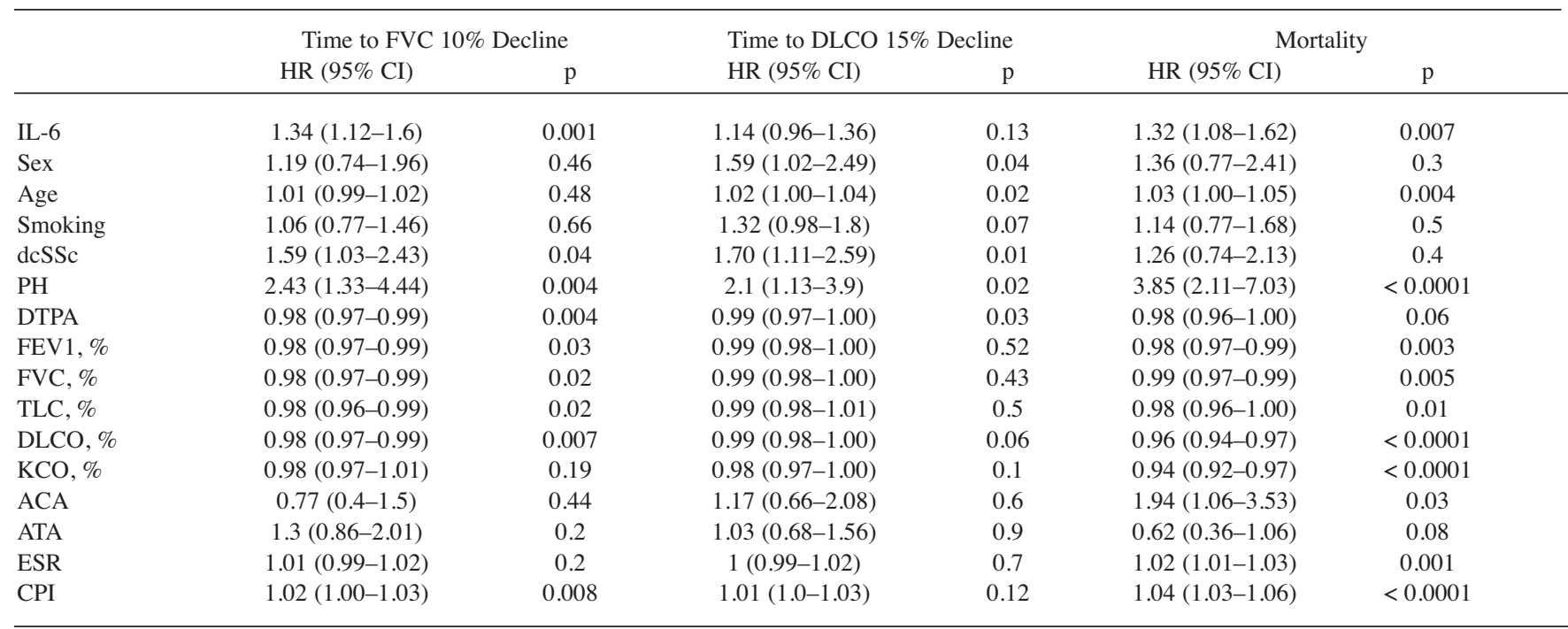

dcSSc: diffuse cutaneous SSc; PH: presence of pulmonary hypertension; CPI: composite physiologic index 18; ACA: anticentromere antibodies; ATA: antitopoisomerase antibodies; FVC: forced vital capacity; FEV1: forced expiratory volume 1 second; IL: interleukin; DTPA: ${ }^{99 \mathrm{~m}}$ Tc-technetium-labeled diethylene-triamine-pentacetate clearance; KCO: carbon monoxide transfer coefficient corrected for lung volume; ESR: erythrocyte sedimentation rate.

relevant covariates (Table 4), the link between serum IL-6 and time to decline in DLCO was found to be significant (adjusted HR $=1.5,95 \%$ CI $1.002-2.1, \mathrm{p}=0.048$ ). Details on the multivariate analyses can be found in Appendix 2.

Serum IL-6 thresholds against functional decline and survival. We set out to test whether the serum IL-6 threshold of $7.67 \mathrm{pg} / \mathrm{ml}$ observed to be associated with a DLCO decline in the first year in the exploratory set (see above) was also predictive of functional decline in the larger test group. The analysis was performed using Aalen linear hazards models (Appendix 2). In brief, a serum concentration $>7.67 \mathrm{pg} / \mathrm{ml}$ was associated with decline in FVC $(\mathrm{HR}=2.58 \pm 0.98, \mathrm{p}=0.013)$ and decline in DLCO within the first year $(\mathrm{HR}=3.2 \pm 1.7, \mathrm{p}=0.02)$, but not at later timepoints, and with increased mortality within the first 30 months $(\mathrm{HR}=2.58 \pm 0.62, \mathrm{p}<0.0001)$, even after adjustment for covariates, including age, sex, smoking history, CPI, ESR, pulmonary hypertension, diffuse skin disease, and DTPA clearance.

To investigate whether the prognostic utility of serum IL-6 might apply to mild disease, severe disease, or both, we performed an exploratory analysis of the relationship between serum IL-6 and outcome, according to a FVC threshold of $70 \%$, established as the functional severity threshold most predictive of mortality in SSc-ILD ${ }^{5}$. In view of the relatively small subgroup numbers, time to functional decline (FVC and/or DLCO) or death were combined as a single outcome variable. As shown in Figure 1, serum IL-6 $>7.67 \mathrm{pg} / \mathrm{ml}$ was associated with functional decline and/or death within the first year in patients with milder disease (FVC $>70 \%$; i.e., functional deterioration or death in $36 \%$ vs $15 \%$ in those with IL-6 levels above or below $7.67 \mathrm{pg} / \mathrm{ml}$, respectively; $\mathrm{HR}=3.5,95 \% \mathrm{CI} 1.6-7.6, \mathrm{p}=0.002)$, but not in those with severe disease (FVC $<70 \%$; i.e., disease progression or death in $39 \%$ vs $47 \%$ in those with IL-6 levels above or below $7.67 \mathrm{pg} / \mathrm{ml}$, respectively; $\mathrm{p}=0.7$ ). These associations and their effect size did not change after adjustment for sex, age, smoking status, CPI, ESR, and pulmonary hypertension. Progression was seen in $15 \%$ in those with mild ILD and low serum IL-6, in contrast to progression observed in about $40 \%$ of patients with mild ILD/high IL-6, and of those with severe ILD regardless of serum IL-6.

\section{DISCUSSION}

The discovery of informative, noninvasive biomarkers is particularly relevant in SSc-ILD, where there is a need to detect likelihood of ILD progression early in the disease. By investigating a variety of serum cytokines as possible biomarkers, we found a significant association between serum IL-6 levels and ILD progression/mortality in a large cohort of well-characterized patients with SSc-ILD with longterm functional followup.

A number of cytokines, alveolar epithelial markers, and acute-phase reactants have been suggested as markers of lung fibrosis in the context of $\mathrm{SSc}^{4,9,22,23,24,25}$. Serum epithelial markers KL-6 and surfactant protein D, as well as CCL18, a marker of alveolar macrophage activation, have been variously found to be correlated with ILD severity and disease progression ${ }^{9,22,24,25}$, while surfactant protein-A (SP-A) was predictive of early mortality in patients with $\mathrm{IPF}^{26}$. Similarly, CRP and/or ESR have been linked to lung involvement in $\mathrm{SSc}^{4,23,27}$. However, only a few studies have assessed whether serum biomarkers can predict longitudinal 

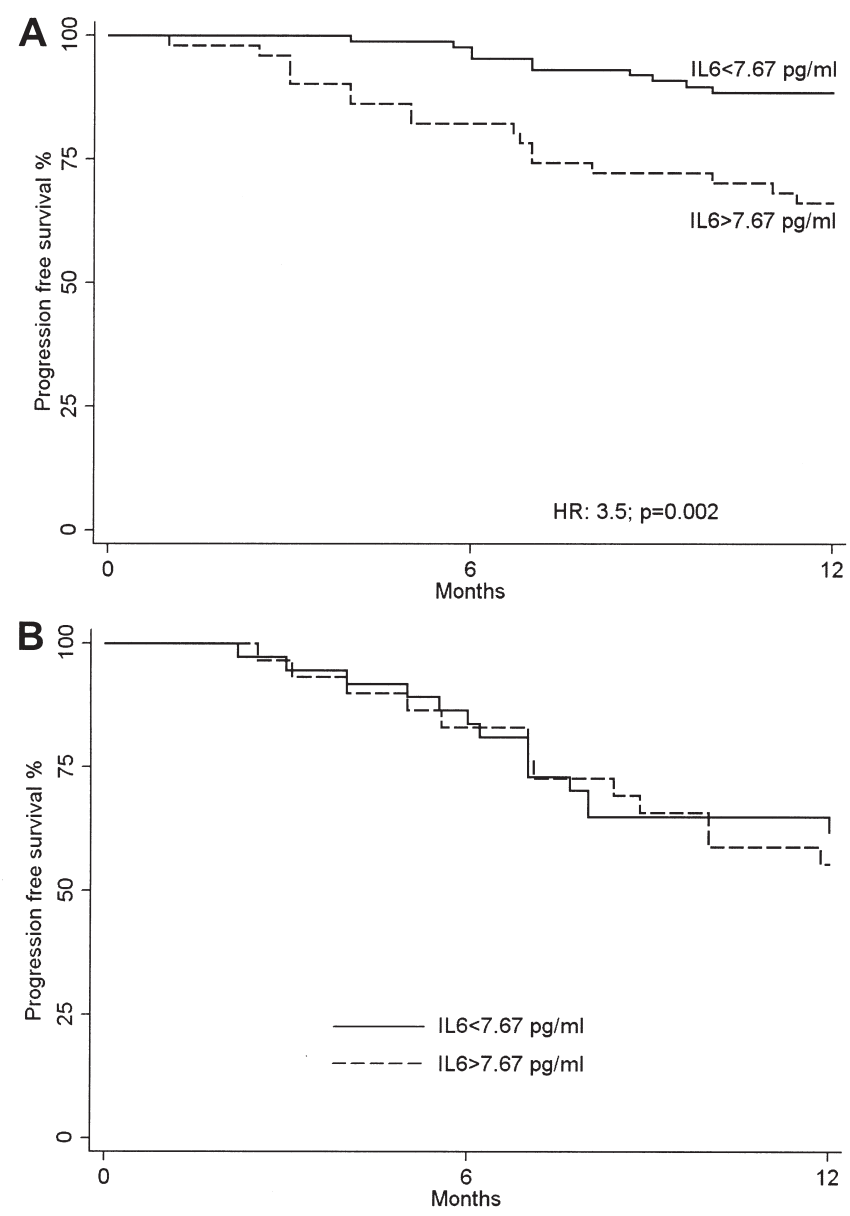

Figure 1. Kaplan-Meier curves illustrate time to decline in functional decline or death ("progression-free survival") in the first year according to serum IL-6 threshold of $7.67 \mathrm{pg} / \mathrm{ml}$ in patients with SSc-ILD, subdivided into those with milder disease ( $\mathrm{FVC} \geq 70 \%$; $\mathrm{A}$ ) and those with more severe disease (FVC $<70$; B). A. In patients with FVC $\geq 70 \%$, serum IL-6 $>7.67$ $\mathrm{pg} / \mathrm{ml}$ is predictive of significantly shorter progression-free survival (HR $3.5, \mathrm{p}=0.002)$. B. In patients with $\mathrm{FVC}<70 \%$, no difference in progression-free survival is seen according to serum IL-6 levels. SSc-ILD: scleroderma-associated interstitial lung disease; IL: interleukin; FVC: forced vital capacity.

behavior, and whether the predictive value is maintained after adjustment for lung disease severity, a well-known prognostic marker ${ }^{27}$.

The finding that IL-6 predicted early outcome selectively in milder disease is important. However, this observation will require further testing in an independent cohort, because it is derived from an exploratory, posthoc analysis. The Goh staging system identifies about $40 \%$ of patients with a striking increase in mortality ${ }^{5}$. In this subgroup, treatment to stabilize disease is likely to be warranted, irrespective of biomarker data, because the lung fibrosis is likely to progress regardless of serum IL-6 status. By contrast, the remaining $60 \%$ of patients with "mild disease" present a major dilemma to the clinician. Inevitably, some of these patients must progress in time to extensive disease with a worse outcome, especially those who lie close to the threshold for identifying extensive disease. Such patients should be treated early to prevent progression to extensive disease, whereas patients with mild disease at low risk of progression should be carefully observed. The findings from our study suggest that IL-6 might serve as a valuable prognostic biomarker in this context.

The analysis of the test cohort showed that elevated IL-6 was predictive of a decline in FVC and/or DLCO within the first year, and of death within the first 30 months. The lack of association with progression at later timepoints suggests that IL-6 might signal the onset of phases of disease progression, rather than mark different phenotypes of the disease constitutively characterized by a different prognosis. Interestingly, a greater predictive effect in earlier timepoints since measurement has also been described for SP-A protein in $\mathrm{IPF}^{26}$ and for bronchoalveolar lavage neutrophilia in SSc-ILD ${ }^{16}$.

Other acute-phase reactants, including ESR and CRP, have been shown to be predictive of poor survival in $\mathrm{SSc}^{23,28,29}$. Indeed, in our study, we confirmed that ESR was predictive of mortality in the larger test set but not of SSc-ILD progression. Interestingly, IL-6 remained predictive of early mortality even after adjustment for ESR, suggesting that serum IL-6 may add useful prognostic information beyond that of other common acute-phase reactants.

In the exploratory set, we identified a number of positive associations between serum cytokines and progression of lung fibrosis, in part confirming previous reports ${ }^{22,30}$, although many of the associations were no longer significant after correction for multiple comparisons. The finding that a number of predominantly inflammatory biomarkers correlated significantly with baseline disease severity in IPF is interesting, and highlights a potential role for inflammatory responses. Serum IL-6 was associated with DLCO decline even after adjustment by disease severity and correction for multiple comparisons, without differences between SSc and IPF, and was therefore considered a good biomarker candidate to be investigated further.

That serum IL-6 predicts functional decline in IPF suggests that it should also be evaluated further as a potentially valuable biomarker in patients with IPF. Collard, et al reported increased levels of serum IL-6, together with serum markers of type II epithelial cells and other cytokines, during acute exacerbations of $\mathrm{IPF}^{31}$. Studies have suggested a role for IL-6 in promoting fibrosis, and increased levels of IL-6 have been reported in the serum, bronchoalveolar lavage, and skin biopsies of patients with $\mathrm{SSc}^{32,33,34,35,36}$. Lung fibrosis induced by irradiation or bleomycin therapy is attenuated in IL-6 gene knockout mice ${ }^{37}$.

Our observation that serum IL-6 remains predictive of functional decline even after adjustment for clearance of DTPA, a marker of pulmonary epithelial injury recently described as a powerful predictor of time to FVC decline in

Personal non-commercial use only. The Journal of Rheumatology Copyright @ 2013 . All rights reserved. 
SSc patients ${ }^{6}$, suggests that IL-6 levels may be identifying nonepithelial events. These may be related to lymphomonocytic lineages, lung fibroblasts, and/or the crosstalk between the two. Of note, IL- 6 shifts T cells from regulatory responses to pathogenic Th17 responses ${ }^{38}$, and promotes the differentiation of CD4+ cells to a profibrotic Th2 type while suppressing Th1 differentiation ${ }^{39}$. IL-6 production by lung fibroblasts is enhanced by co-culture with SSc lung-derived B cells ${ }^{40}$. IL-6 stimulation induces increased collagen production in dermal fibroblasts ${ }^{40,41}$ and in the liver ${ }^{42}$. IL-6 inhibited apoptosis in IPF but not in control lung fibroblasts, suggesting a specifically altered IL-6 signaling pathway in lung fibrosis ${ }^{43}$.

A number of limitations should be considered when interpreting our findings. Serum biomarkers provide a "snapshot" assessment that can be influenced by a variety of extrapulmonary factors, including age, time of day, and intercurrent viral infections or other inflammatory conditions. In particular, serum IL-6 is also an acute-phase protein and, at least in some cases, may be elevated because of acute intercurrent events independent of SSc and its progression. Further, in the context of scleroderma, serum biomarkers could easily reflect extrapulmonary disease activity. Tissue IL-6 levels are increased in severe skin disease ${ }^{34}$, and B cell depletion induced by rituximab was associated with reduced serum IL-6 in parallel with improvement of skin disease, suggesting a role for IL- 6 in scleroderma skin fibrosis ${ }^{44}$. The link between serum IL- 6 and early mortality in patients with SSc could therefore be related to more severe systemic disease, in addition to progression of ILD. However, the persistence of an association between IL-6 and ILD progression even after adjustment for pulmonary hypertension and for diffuse skin disease, 2 powerful risk factors for mortality in SSc, and confirmation of the association in 2 separate cohorts suggest that despite the inherent variability of a serum marker, serum IL-6 is linked with lung disease activity. Finally, the sensitivity and specificity of the identified IL-6 threshold as a predictor of early DLCO decline were suboptimal. There are a number of possible explanations for this. IL-6 is likely to be only one of a number of variables contributing to progression of lung fibrosis, and there could be SSc patient subsets where IL-6 plays a more prominent role in disease progression. In addition, other variables such as intercurrent infections can also cause elevations in serum IL-6, thereby increasing the noise of measurement and reducing its specificity.

A significant association between IL- 6 and mortality was seen only in our test set; the lack of a significant association in the exploratory group could be related to smaller patient numbers, with only 8 deaths occurring in the SSc group and 19 in the IPF group in the exploratory set in the first 3 years.

Serum IL-6 measurement may be a noninvasive independent predictor of early ILD progression and mortality in SSc patients with milder ILD, enabling targeting of treatment for the patients with early disease most likely to progress. Prospective studies are needed to confirm these conclusions and to evaluate the role of IL-6 in lung fibrosis, to assess whether there could be a role for anti-IL-6 treatment in SSc-ILD.

\section{ACKNOWLEDGMENT}

The authors thank Anna L. Logan for providing multiplex kits and Athena Gogali for logistic support.

\section{REFERENCES}

1. de Lauretis A, Veeraraghavan S, Renzoni E. Review series: aspects of interstitial lung disease: connective tissue disease-associated interstitial lung disease: how does it differ from IPF? How should the clinical approach differ? Chron Respir Dis 2011;8:53-82.

2. Ferri C, Valentini G, Cozzi F, Sebastiani M, Michelassi C, La MG, et al. Systemic sclerosis: demographic, clinical, and serologic features and survival in 1,012 Italian patients. Medicine 2002;81:139-53.

3. Steen VD, Medsger TA. Changes in causes of death in systemic sclerosis, 1972-2002. Ann Rheum Dis 2007;66:940-4.

4. Steen VD, Conte C, Owens GR, Medsger TA Jr. Severe restrictive lung disease in systemic sclerosis. Arthritis Rheum 1994;37:1283-9.

5. Goh NS, Desai SR, Veeraraghavan S, Hansell DM, Copley SJ, Maher TM, et al. Interstitial lung disease in systemic sclerosis: a simple staging system. Am J Respir Crit Care Med 2008;177: 1248-54.

6. Goh NS, Desai SR, Anagnostopoulos C, Hansell DM, Hoyles RK, Sato $\mathrm{H}$, et al. Increased epithelial permeability in pulmonary fibrosis in relation to disease progression. Eur Respir J 2011;38:184-90.

7. Hant FN, Ludwicka-Bradley A, Wang HJ, Li N, Elashoff R, Tashkin DP, et al. Surfactant protein D and KL-6 as serum biomarkers of interstitial lung disease in patients with scleroderma. J Rheumatol 2009;36:773-80.

8. Takahashi H, Fujishima T, Koba H, Murakami S, Kurokawa K, Shibuya Y, et al. Serum surfactant proteins A and D as prognostic factors in idiopathic pulmonary fibrosis and their relationship to disease extent. Am J Respir Crit Care Med 2000;162:1109-14.

9. Tiev KP, Hua-Huy T, Kettaneh A, Gain M, Duong-Quy S, Toledano $\mathrm{C}$, et al. Serum CC chemokine ligand-18 predicts lung disease worsening in systemic sclerosis. Eur Respir J 2011;38:1355-60.

10. Wells AU, Cullinan P, Hansell DM, Rubens MB, Black CM, Newman-Taylor AJ, et al. Fibrosing alveolitis associated with systemic sclerosis has a better prognosis than lone cryptogenic fibrosing alveolitis. Am J Respir Crit Care Med 1994;149:1583-90.

11. Beirne P, Pantelidis P, Charles P, Wells AU, Abraham DJ, Denton $\mathrm{CP}$, et al. Multiplex immune serum biomarker profiling in sarcoidosis and systemic sclerosis. Eur Respir J 2009;34:1376-82.

12. Renzoni EA, Abraham DJ, Howat S, Shi-Wen X, Sestini P, Bou-Gharios $\mathrm{G}$, et al. Gene expression profiling reveals novel TGF-beta targets in adult lung fibroblasts. Respir Res 2004;5:24.

13. Preliminary criteria for the classification of systemic sclerosis (scleroderma). Subcommittee for scleroderma criteria of the American Rheumatism Association Diagnostic and Therapeutic Criteria Committee. Arthritis Rheum 1980;23:581-90.

14. American Thoracic Society. Idiopathic pulmonary fibrosis: diagnosis and treatment. International consensus statement. American Thoracic Society (ATS), and the European Respiratory Society (ERS). Am J Respir Crit Care Med 2000;161:646-64.

15. Desai SR, Veeraraghavan S, Hansell DM, Nikolakopolou A, Goh NS, Nicholson AG, et al. CT features of lung disease in patients with systemic sclerosis: Comparison with idiopathic pulmonary 
fibrosis and nonspecific interstitial pneumonia. Radiology 2004;232:560-7.

16. Goh NS, Veeraraghavan S, Desai SR, Cramer D, Hansell DM, Denton CP, et al. Bronchoalveolar lavage cellular profiles in patients with systemic sclerosis-associated interstitial lung disease are not predictive of disease progression. Arthritis Rheum 2007;56:2005-12.

17. Wells AU, Rubens MB, du Bois RM, Hansell DM. Serial CT in fibrosing alveolitis: Prognostic significance of the initial pattern. AJR Am J Roentgenol 1993;161:1159-65.

18. Wells AU, Desai SR, Rubens MB, Goh NS, Cramer D, Nicholson AG, et al. Idiopathic pulmonary fibrosis: A composite physiologic index derived from disease extent observed by computed tomography. Am J Respir Crit Care Med 2003;167:962-9.

19. Corte TJ, Wort SJ, Gatzoulis MA, Macdonald P, Hansell DM, Wells AU. Pulmonary vascular resistance predicts early mortality in patients with diffuse fibrotic lung disease and suspected pulmonary hypertension. Thorax 2009;64:883-8.

20. American Thoracic Society/European Respiratory Society international multidisciplinary consensus classification of the idiopathic interstitial pneumonias. This joint statement of the American Thoracic Society (ATS), and the European Respiratory Society (ERS) was adopted by the ATS board of directors, June 2001 and by the ERS Executive Committee, June 2001. Am J Respir Crit Care Med 2002;165:277-304.

21. Hosmer DW, Royston P. Using Aalen's linear hazards model to investigate time-varying effects in the proportional hazards regression model. Stata J 2002;2:331-50.

22. Antoniou KM, Tzouvelekis A, Alexandrakis MG, Sfiridaki K, Tsiligianni I, Rachiotis G, et al. Different angiogenic activity in pulmonary sarcoidosis and idiopathic pulmonary fibrosis. Chest 2006;130:982-8.

23. Muangchan C, Harding S, Khimdas S, Bonner A, Baron M, Pope J. Association of C-reactive protein with high disease activity in systemic sclerosis: Results from the Canadian Scleroderma Research Group. Arthritis Care Res 2012;64:1405-14.

24. Sato S, Nagaoka T, Hasegawa M, Nishijima C, Takehara K. Elevated serum KL-6 levels in patients with systemic sclerosis: association with the severity of pulmonary fibrosis. Dermatology 2000;200:196-201

25. Yanaba K, Hasegawa M, Takehara K, Sato S. Comparative study of serum surfactant protein-D and KL-6 concentrations in patients with systemic sclerosis as markers for monitoring the activity of pulmonary fibrosis. J Rheumatol 2004;31:1112-20.

26. Kinder BW, Brown KK, McCormack FX, Ix JH, Kervitsky A, Schwarz MI, et al. Serum surfactant protein-A is a strong predictor of early mortality in idiopathic pulmonary fibrosis. Chest 2009;135:1557-63.

27. Lota HK, Renzoni EA. Circulating biomarkers of interstitial lung disease in systemic sclerosis. Int J Rheumatol 2012;2012:121439.

28. Bryan C, Knight C, Black CM, Silman AJ. Prediction of five-year survival following presentation with scleroderma: Development of a simple model using three disease factors at first visit. Arthritis Rheum 1999;42:2660-5.

29. Fransen J, Popa-Diaconu D, Hesselstrand R, Carreira P, Valentini G, Beretta L, et al. Clinical prediction of 5-year survival in systemic sclerosis: validation of a simple prognostic model in EUSTAR centres. Ann Rheum Dis 2011;70:1788-92.
30. Sato S, Hasegawa M, Takehara K. Serum levels of interleukin-6 and interleukin-10 correlate with total skin thickness score in patients with systemic sclerosis. J Dermatol Sci 2001;27:140-6.

31. Collard HR, Calfee CS, Wolters PJ, Song JW, Hong SB, Brady S, et al. Plasma biomarker profiles in acute exacerbation of idiopathic pulmonary fibrosis. Am J Physiol Lung Cell Mol Physiol 2010;299:L3-7.

32. De Santis M, Bosello S, La TG, Capuano A, Tolusso B, Pagliari G, et al. Functional, radiological and biological markers of alveolitis and infections of the lower respiratory tract in patients with systemic sclerosis. Respir Res 2005;6:96.

33. Hasegawa M, Sato S, Fujimoto M, Ihn H, Kikuchi K, Takehara K. Serum levels of interleukin 6 (IL-6), oncostatin M, soluble IL-6 receptor, and soluble gp130 in patients with systemic sclerosis. J Rheumatol 1998;25:308-13.

34. Koch AE, Kronfeld-Harrington LB, Szekanecz Z, Cho MM, Haines GK, Harlow LA, et al. In situ expression of cytokines and cellular adhesion molecules in the skin of patients with systemic sclerosis. Their role in early and late disease. Pathobiology 1993;61:239-46.

35. Muangchan C, Pope JE. Interleukin 6 in systemic sclerosis and potential implications for targeted therapy. J Rheumatol 2012;39:1120-4.

36. Scala E, Pallotta S, Frezzolini A, Abeni D, Barbieri C, Sampogna F, et al. Cytokine and chemokine levels in systemic sclerosis: Relationship with cutaneous and internal organ involvement. Clin Exp Immunol 2004;138:540-6

37. Saito-Fujita T, Iwakawa M, Nakamura E, Nakawatari M, Fujita H, Moritake T, et al. Attenuated lung fibrosis in interleukin 6 knock-out mice after C-ion irradiation to lung. J Radiat Res 2011;52:270-7.

38. Laurence A, O'Shea JJ. T(H)-17 differentiation: Of mice and men. Nat Immunol 2007;8:903-5.

39. Glimcher LH, Murphy KM. Lineage commitment in the immune system: The T helper lymphocyte grows up. Genes Dev 2000;14:1693-711.

40. Kondo K, Okada T, Matsui T, Kato S, Date K, Yoshihara M, et al. Establishment and characterization of a human B cell line from the lung tissue of a patient with scleroderma; extraordinary high level of IL-6 secretion by stimulated fibroblasts. Cytokine 2001; 13:220-6.

41. Duncan MR, Berman B. Stimulation of collagen and glycosaminoglycan production in cultured human adult dermal fibroblasts by recombinant human interleukin 6. J Invest Dermatol 1991;97:686-92.

42. Choi I, Kang HS, Yang Y, Pyun KH. IL-6 induces hepatic inflammation and collagen synthesis in vivo. Clin Exp Immunol 1994;95:530-5.

43. Knight D, Mutsaers SE, Prele CM. STAT3 in tissue fibrosis: Is there a role in the lung? Pulm Pharmacol Ther 2011;24:193-8.

44. Bosello S, De Santis M, Lama G, Spano C, Angelucci C, Tolusso $\mathrm{B}$, et al. B cell depletion in diffuse progressive systemic sclerosis: Safety, skin score modification and IL-6 modulation in an up to thirty-six months follow-up open-label trial. Arthritis Res Ther 2010;12:R54 
Appendix 1. Scatterplots for 8 cytokines measured in the exploratory set in 20 controls, 58 patients with idiopathic pulmonary fibrosis (IPF), and 74 patients with systemic sclerosis (SSc). ${ }^{*} \mathrm{p}=0.01-0.05 ; * * \mathrm{p}=$ $0.001-0.01 ; * * * \mathrm{p}=0.0001$ vs controls; ${ }^{\#} \mathrm{p}=0.02$ vs IPF. CCL2: chemokine (C-C motif) ligand 2; CXCL10: chemokine (C-X-C motif) ligand 10; VEGF: vascular endothelial growth factor; FGF2: fibroblast growth factor 2; CX3CL1: chemokine (C-X3-C motif) ligand 1; IL: interleukin.
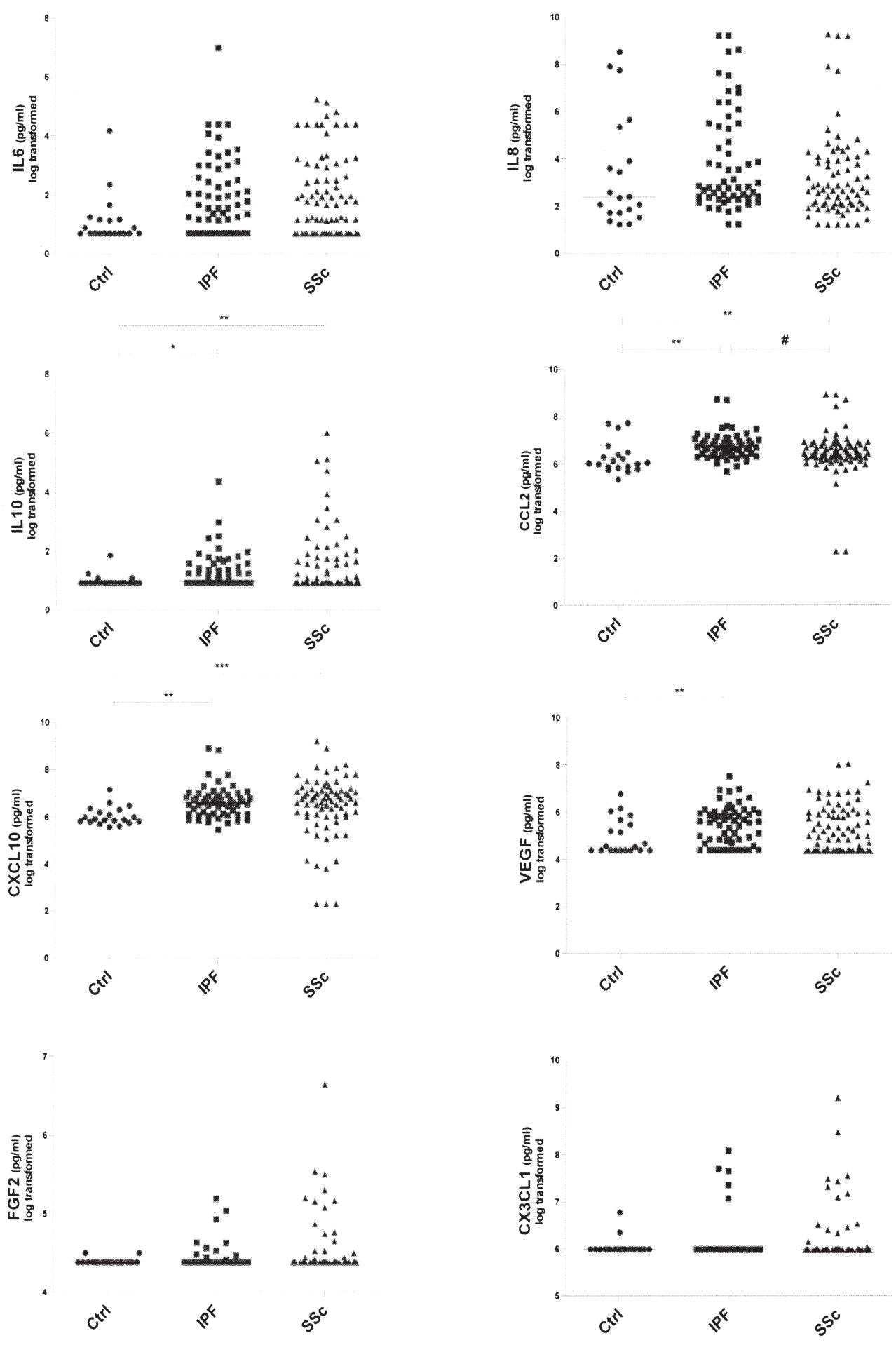


\section{Appendix 2. Supplementary results.}

Serum cytokines in the exploratory set. Serum levels of IL-6 and CXCL10 were significantly higher in both SSc and IPF patients compared to controls, even after Bonferroni correction for multiple testing (IL-6: SSc vs control, $\mathrm{p}_{\mathrm{c}}=0.01 ;$ IPF vs control, $\mathrm{p}_{\mathrm{c}}=0.02 ;$ CXCL10: SSc vs control, $\mathrm{p}_{\mathrm{c}}$ $=0.01 ;$ IPF vs control, $\left.\mathrm{p}_{\mathrm{c}}<0.0008\right)$. CCL2 was significantly higher in IPF $\left(p_{c}=0.002\right)$, while bordering on significance in $\operatorname{SSc}\left(p_{c}=0.054\right)$, compared to controls (Table 2, Appendix 1).

Significant correlations were observed between most serum cytokines, as shown by the correlation matrix in Appendix 3. The strongest correlations $(r>0.45)$ were seen between IL- 6 and IL-10 $(r=0.59)$, CCL2 $(r=$ $0.47)$, and VEGF $(r=0.49)$. ESR correlated weakly, among all cytokines, only with IL-6 $\left(r=0.2, \mathrm{p}_{\mathrm{c}}=0.16\right.$; Appendix 3$)$.

In both SSc and IPF, serum IL-6 levels were inversely correlated to percentage predicted FVC $\left(p_{c}=0.006, p_{c}=0.02\right.$, respectively). IL- 6 was also correlated with the CPI $\left(\mathrm{p}_{\mathrm{c}}=0.006\right.$ and $\mathrm{p}_{\mathrm{c}}=0.08$ in IPF and SSc, respectively; Appendix 4). Correlations and observed trends between CCL2, IL-10, CXCL10, and FGF2 with FVC and/or DLCO and/or the CPI were also observed in both SSc and IPF. IL-8 serum levels were significantly correlated with all functional severity indices in IPF, but not in SSc (Appendix 4).

Of note, ESR did not correlate with any lung function measure (Appendix 4).

Test set: serum IL-6 analyzed as a continuous variable against survival. On univariate analysis, a shorter survival was significantly associated with serum IL-6 levels (HR 1.32, 95\% CI 1.08-1.62, p = 0.007; Table 4). Other predictors included age, severity of lung disease (assessed by CPI, lung volumes, or DLCO), presence of anticentromere antibodies (ACA), ESR, and pulmonary hypertension (Table 4). After adjustment for covariates associated with survival on univariate analysis (age, CPI, pulmonary hypertension, ESR, and ACA positivity), the association between serum IL-6 and mortality bordered on significance (adjusted HR $1.24,95 \%$ CI $0.98-1.58, \mathrm{p}=0.077$ ). However, the association between serum IL-6 and early mortality remained significant, even after adjustment for age, CPI, pulmonary hypertension, ESR, and ACA positivity [whether calculated at 12 months (adjusted HR 1.9, 95\% CI 1.13-3.3, $\mathrm{p}=0.02$; or at 30 months (adjusted HR 1.79, 95\% CI 1.3-2.5, p = 0.001)].

Test set: serum IL-6 analyzed as a continuous variable against time to decline in pulmonary function measures. On univariate analysis, serum IL-6 was associated with a shorter time to decline in FVC (HR 1.34, 95\% CI 1.12-1.61, p = 0.001; Table 4). A trend for association between serum IL-6 levels and time to decline in DLCO was also observed, although this did not achieve statistical significance (Table 4). Other predictors of time to decline of FVC and/or DLCO included baseline severity markers (CPI, FVC, FEV1, total lung capacity, and DLCO), DTPA clearance, pulmonary hypertension, and diffuse skin disease (Table 4). Serum ESR was not predictive of decline in either DLCO or FVC. Serum IL-6 levels remained significantly predictive of time to decline in FVC after adjustment for age, sex, smoking status, treatment, DTPA clearance, pulmonary hypertension, diffuse skin disease, and lung disease severity (measured by CPI; adjusted HR 1.4, 95\% CI 1.08-1.86, p = 0.01). After adjustment for the same covariates, the link between serum IL-6 and time to decline in DLCO was also found to reach significance (adjusted HR 1.5, 95\% CI 1.002-2.1, p = 0.048).
Test set: serum IL-6 thresholds against ILD progression and survival analysis of time trends. We set out to test whether the serum IL-6 threshold of $7.67 \mathrm{pg} / \mathrm{ml}$ observed to be associated with a DLCO decline in the first year in the exploratory set was also predictive of functional decline in the larger test group. To formally assess whether the relationship between serum IL-6 levels and time to disease deterioration or mortality varied according to the time interval from serum measurement, we examined the time trend of the association between levels of IL- $6>7.67 \mathrm{pg} / \mathrm{ml}$ and functional decline/mortality using Aalen's linear hazards models. Inspection of plots of cumulative regression coefficients by this method suggested an association between increased level of serum IL-6 and separately, either DLCO (Appendix 5, panel A) or FVC decline (Appendix 5 , panel B) that was indeed limited to roughly the first 12 months. A DLCO decline occurred within a year in $21 \%$ of the patients with serum IL-6 levels above $7.67 \mathrm{pg} / \mathrm{ml}$ and in $8 \%$ of those below the threshold.

Accordingly, a Cox regression model for DLCO decline using 2 time-varying covariates ( $\leq 12$ months and $>12$ months) confirmed these results for the first 12 months (HR $3.2 \pm 1.7, \mathrm{p}=0.02$ ) and showed a nonsignificant effect at later timepoints $(\mathrm{HR} 1.29 \pm 0.37, \mathrm{p}=0.4)$. The effect in the first 12 months remained significant after adjustment for age, sex, smoking history, CPI, pulmonary hypertension, ESR, diffuse skin disease, and DTPA clearance.

Similar results were obtained with FVC decline, where the plot of the cumulative regression coefficient also suggested an association between increased level of serum IL- 6 and FVC decline that was limited to roughly the first 12 months. FVC decline within a year occurred in $25 \%$ of the patients with IL- 6 levels above the threshold, and in $11 \%$ of those below. In a Cox model, a serum level of IL-6 $>7.67 \mathrm{pg} / \mathrm{ml}$ was significantly associated to FVC decline in the subsequent 12 months (HR $2.58 \pm 0.98$, $\mathrm{p}=0.013$ ), but not at later timepoints (HR $1.45 \pm 0.40, \mathrm{p}=0.18$ ). Again, the effect remained significant after adjustment for demographic variables, smoking history, CPI, pulmonary hypertension, ESR, diffuse skin disease, and DTPA clearance.

We also tested the association between elevated serum IL-6 levels and survival using the same methods as above. Inspection of the plot of cumulative regression coefficients estimated by Aalen's linear hazards model showed that elevated serum IL-6 levels are associated with increased mortality within roughly the first 30 months (Appendix 5, panel C). A Cox regression using 3 time-varying covariates ( $<12$ months, 12 to 30 months, and $>30$ months) showed a significant association between elevated serum IL- 6 and death occurring in the first 12 months (HR $2.49 \pm$ $0.81, \mathrm{p}=0.005$ ) and between 12 and 30 months (HR $2.69 \pm 0.96, \mathrm{p}=$ $0.005)$, while by contrast no significant effect was observed at later timepoints (HR $1.16 \pm 0.29, \mathrm{p}=0.544)$. Overall, the HR for the risk of death in the first 30 months was $2.58 \pm 0.62(\mathrm{p}<0.0001)$; this remained significant after adjustment for demographic variables, smoking history, CPI, ESR, and pulmonary hypertension.

Finally, repeat ROC analyses performed in the confirmatory set to detect the risk of functional decline (DLCO and/or FVC decline) within a year and of early mortality yielded optimal thresholds of $8.42 \mathrm{pg} / \mathrm{ml}$ and $7.72 \mathrm{pg} / \mathrm{ml}$, respectively, both very similar to that estimated in the exploratory set. Kaplan-Meier curves illustrating time to decline in FVC and/or DLCO and survival according to these thresholds are shown in Appendix 6 and Appendix 7. 
Appendix 3. Correlations between cytokines in the exploratory set. Correlations expressed with Spearman's rho/point-biserial r/phi.

\begin{tabular}{|c|c|c|c|c|c|c|c|c|}
\hline IL-6 & 1 & & & & & & & \\
\hline IL-8 & $0.42^{* * \dagger}$ & 1 & & & & & & \\
\hline IL-10 & $0.59 * * \dagger$ & $0.23 *$ & $0.36^{* * \dagger}$ & 1 & & & & \\
\hline CXCL10 & $0.42 * * \dagger$ & $0.20 *$ & $0.41 * * \dagger$ & $0.41 * * \dagger$ & 1 & & & \\
\hline VEGF & $0.49 * * \dagger$ & $0.37 * * \dagger$ & $0.35^{* * \dagger}$ & $0.41 * * \dagger$ & $0.32 * * \dagger$ & 1 & & \\
\hline ESR & $0.22 *$ & NS & NS & NS & NS & NS & NS & NS \\
\hline
\end{tabular}

$* 0.0001 \leq \mathrm{p} \leq 0.02 ; * * \mathrm{p}<0.0001 ; * *$ Dichotomous variables. ${ }^{\dagger}$ Significant after Bonferroni correction. NS: not significant; IL: interleukin; VEGF: vascular endothelial growth factor; FGF2: fibroblast growth factor 2; CCL2: chemokine (C-C motif) ligand 2; CXCL10: chemokine (C-X-C motif) ligand 10; CX3CL1: chemokine (C-X3-C motif) ligand 1; ESR: erythrocyte sedimentation rate.

Appendix 4. Correlation between lung function severity indices and serum cytokine levels in SSc and IPF.

\begin{tabular}{|c|c|c|c|c|c|c|}
\hline & IPF & SSc & IPF & SSc & IPF & SSc \\
\hline IL-6 & $-0.43(0.0007)^{\dagger}$ & $-0.35(0.002)^{\dagger}$ & $-0.31(0.02)$ & $-0.23(0.05)$ & $0.43(0.0007)^{\dagger}$ & $0.29(0.01)$ \\
\hline CCL2 & $-0.35(0.006)^{\dagger}$ & $-0.26(0.03)$ & $-0.33(0.01)$ & NS & $0.38(0.003)^{\dagger}$ & $0.26(0.02)$ \\
\hline IL-10 & $-0.27(0.04)$ & $-0.29(0.01)$ & NS & NS & $0.29(0.03)$ & $0.27(0.02)$ \\
\hline CXCL10 & $-0.28(0.03)$ & NS & NS & NS & $0.25(0.05)$ & $0.24(0.04)$ \\
\hline CX3CL1* & $-0.25(0.05)$ & NS & NS & NS & NS & NS \\
\hline ESR & NS & NS & NS & NS & NS & NS \\
\hline
\end{tabular}

$*$ Analyzed as dichotomous variables. Spearman correlation for all variables, except for * point-biserial coefficient of correlation. ${ }^{\dagger}$ Significant after Bonferroni correction. P values reported in parentheses when $\leq 0.05$. IPF: idiopathic pulmonary fibrosis; SSc: systemic sclerosis; FVC: forced vital capacity; CPI: composite physiologic index; NS: not significant; IL: interleukin; VEGF: vascular endothelial growth factor; FGF2: fibroblast growth factor 2; ESR: erythrocyte sedimentation rate; chemokine abbreviations as on Appendix 3. 
Appendix 5. Estimated cumulative regression coefficients for interleukin 6 levels and the pointwise 95\% confidence bands according to DLCO decline (A), FVC decline (B) and risk of death (C). A and B. Plot shows a positive slope up to roughly 12 months, when the lines become horizontal and the lower $95 \%$ $\mathrm{CI}$ are almost invariably below zero, suggesting a nonsignificant effect beyond this timepoint. C. Plot shows a positive slope up to roughly 30 months. After this, the lower 95\% CI gradually decreases to zero. FVC: forced vital capacity.
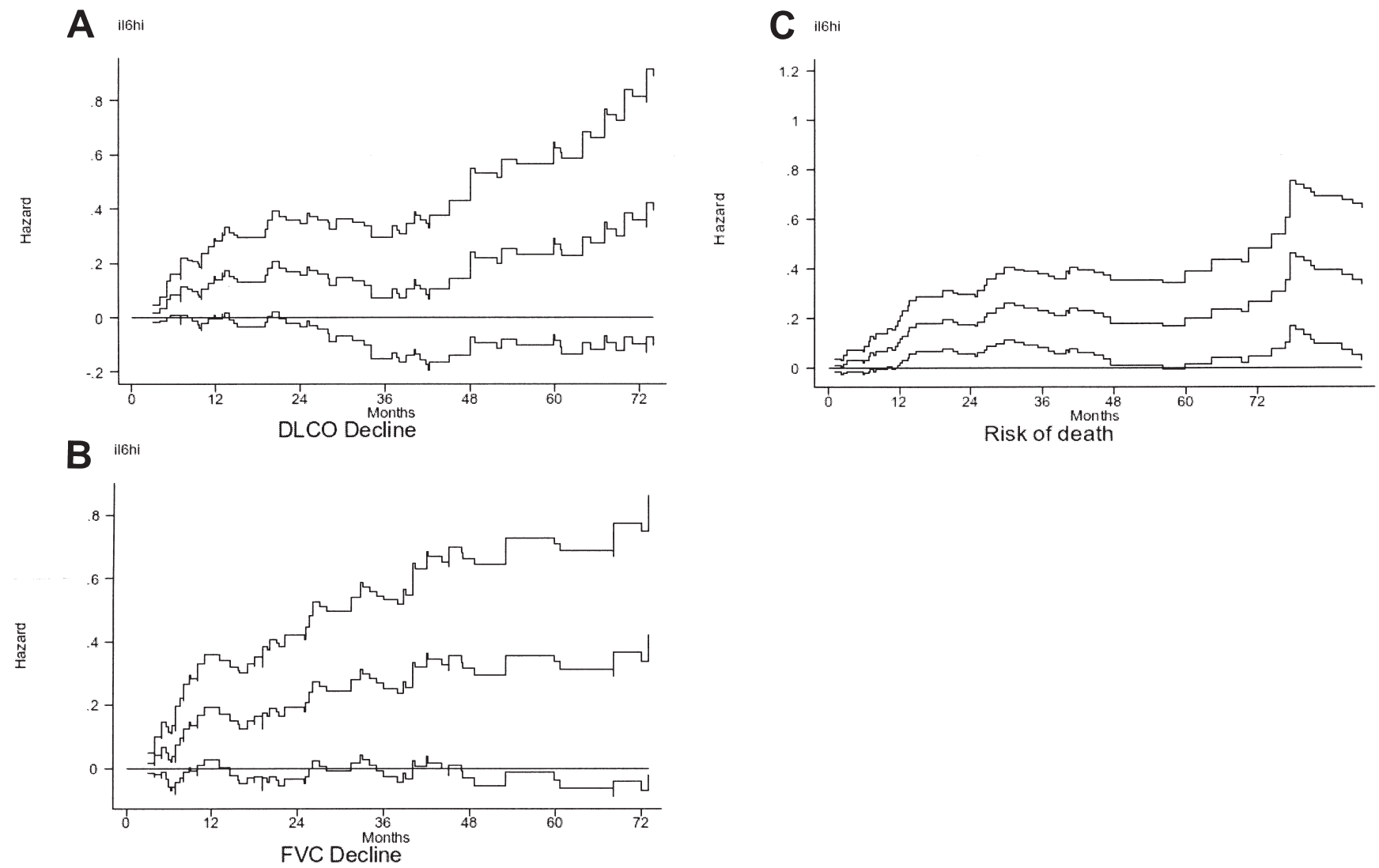

Appendix 6. Kaplan-Meier curves illustrate time to decline in FVC and/or DLCO according to the IL-6 threshold of $8.4 \mathrm{pg} / \mathrm{ml}$ (HR 1.6, p = 0.01), identified by ROC analysis in the test cohort of patients with SSc-ILD. FVC: forced vital capacity; IL: interleukin; ROC: receiver-operator curve; SSc-ILD: scleroderma-associated interstitial lung disease.

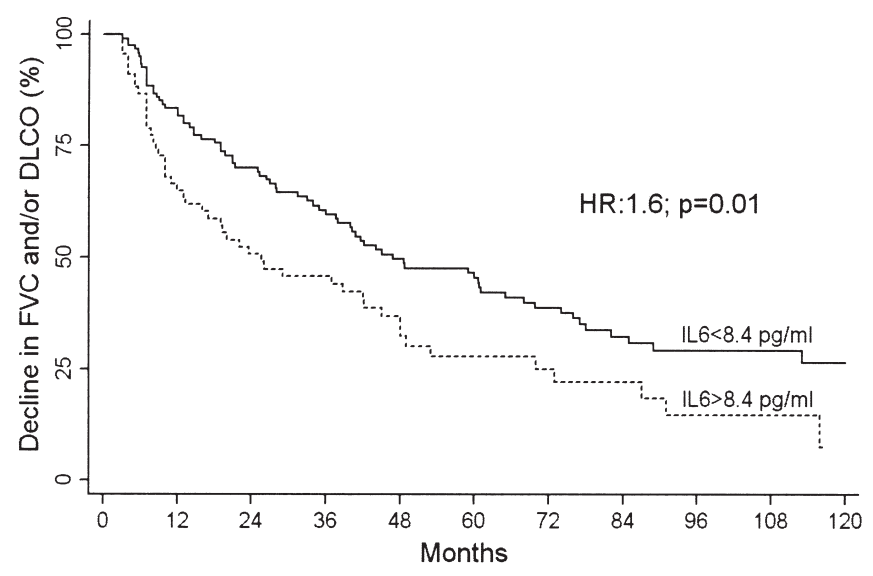

Appendix 7. Kaplan-Meier curves illustrating survival according to the IL-6 threshold of $7.7 \mathrm{pg} / \mathrm{ml}$ (HR 2.04, p = 0.001), identified by ROC analysis in the test cohort of patients with SSc-ILD. IL: interleukin; ROC: receiver-operator curve; SSc-ILD: scleroderma-associated interstitial lung disease.

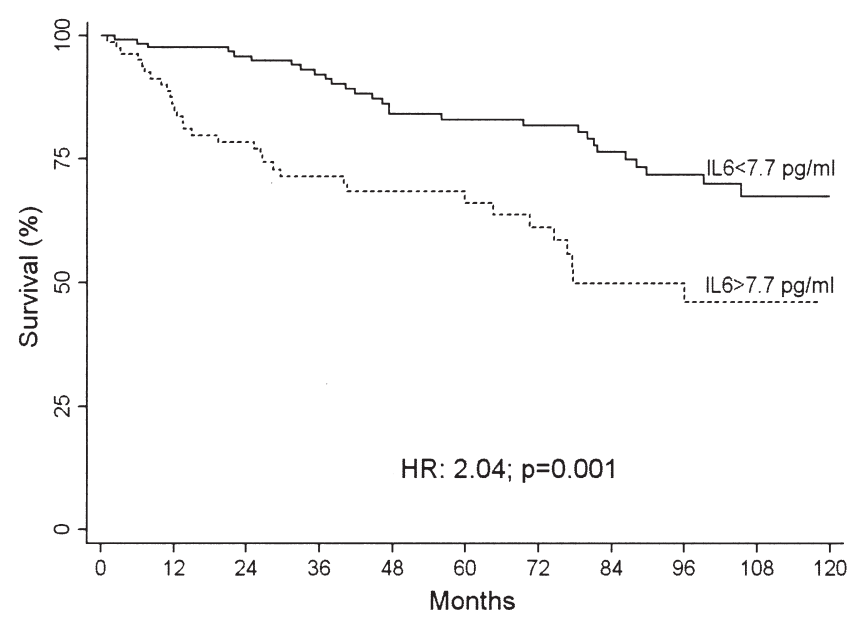

